\title{
Research on the Relationship between Social Support and Employment Quality of Chinese Athletes from the Perspective of Social Network Structure
}

\author{
Meijuan Cao, ${ }^{1}$ Shuairan Li $\mathbb{D},{ }^{1}$ Wenfei Yue, ${ }^{2}$ and Huanqing Wang $\mathbb{C}^{2}$ \\ ${ }^{1}$ Xi'an Physical Education University, Xi'an 710065, China \\ ${ }^{2}$ Sports College, Xi'an University of Architecture and Technology, Xi'an 710311, China \\ Correspondence should be addressed to Shuairan Li; 1929939308@qq.com
}

Received 11 June 2021; Accepted 28 September 2021; Published 14 October 2021

Academic Editor: Shirui Pan

Copyright (C) 2021 Meijuan Cao et al. This is an open access article distributed under the Creative Commons Attribution License, which permits unrestricted use, distribution, and reproduction in any medium, provided the original work is properly cited.

Based on the theories of social network, social support, and retirement process, this study analyzes the source and composition of social support for Chinese athletes on the basis of constructing the social support network. Subsequently, we analyze the impact of social support on employment quality of Chinese athletes from different dimensions and further explore the mechanism of social support on the employment quality of athletes from the moderating role of athletes' self-employment cognition. The study found that the social support network of athletes showed a clear tendency toward "strong ties," and the social support they received mainly came from family members, teammates, and sports team managers. These kinds of social support will directly promote the employment quality of athletes after retirement. When athletes have full knowledge of their future employment status, the effect of social support in promoting employment quality will be further expanded.

\section{Introduction}

In recent years, with the continuous development of China's sports industry, the building of the leading sports nation has become an important strategic move in China's modernization. Competitive sports have always played a leading role in sports undertakings [1]. As the main body of competitive sports, whether athletes can achieve reasonable arrangements at the three key nodes of athlete selection, training, and transfer has become the core of the sustainable development of China's competitive sports. In order to solve the problem of reemployment and placement of athletes in a better way, General Administration of Sport of China has successively introduced a series of important measures. Education, personnel, labor security, and sports departments at all levels have also actively created conditions to broaden the employment channels for retired athletes and guide athletes to adapt to the social needs. Constructing and perfecting the support system for athletes' transformation have been an indispensable part of building the leading sports nation.
Although China has introduced relevant support policies for the professional transformation of retired athletes, the appearance of low employment rate, narrow employment scope, and low-quality employment still embarrasses them. In order to improve the reemployment quality of retired athletes, we must help athletes establish a correct selfawareness of employment first, and various social resources should be given full play. Studies have shown that, among the many factors that affect the personal employment quality, social support has played a very important role in the conversion of personal careers [2]. Similarly, in the career transition process of athletes, the social support system will also affect their smooth employment in terms of psychological adaptation needs, social survival needs, and individual career development needs. Whether athletes succeed in finding high-quality employment opportunities depends on whether they can make good use of social support. Among them, psychological social support will increase athletes' self-evaluation and the possibility of adopting positive coping styles, thereby obtaining better 
reemployment opportunities [3]. It can be seen that social support is a key factor in promoting athletes' employment opportunities.

At present, more and more academic research on the career transformation of athletes is published, but most of it is qualitative research on the transformation and employment status of athletes. Quantitative research on the complex influencing mechanism of athletes' reemployment quality and the sources of influencing factors is less common, especially the empirical research on the impact of social support in athletes' social networks on their reemployment quality. Therefore, in order to explore the influence of mechanism of social support on the reemployment quality of Chinese retired athletes, this study will build a social support network for athletes and clarify the source and composition of social support. The theories of social support and retirement process are the theoretical basis. The impact of social support on the reemployment quality of Chinese athletes is analyzed from different dimensions, and on this basis, the modulating effect of athletes' self-employment cognition is further shown to demonstrate the impact of social support on athletes' reemployment quality. The mechanism of employment quality provides theoretical support and assistance for the proper placement and smooth transition of Chinese athletes after retirement.

\section{An Analysis of Social Support Sources of Chinese Athletes from the Perspective of Social Networks}

In the early 1970s, psychiatric literature introduced the concept of social support, sociology, and medicine using quantitative assessment methods to conduct a large number of studies on the relationship between social support and physical and mental health, and coping with special stress events. However, the connotation has not been uniformly defined within the various disciplines. At present, the academia mainly defines social support as follows: First, it is defined from the perspective of social interactivity. Sarason (1985) deemed that "social support is an objective existence between people or an interactive relationship that an individual can perceive" [4]. Second, from the perspective of social resources, it is believed that social support is "a form of resource exchange, which stems from the help generated by social relations, which is people's contact information or support network members" [5]. Third, from the perspective of social behavior, it is believed that "social support is the response of individuals or groups to the social needs of others. It refers to both the support and help behavior between people and the occurrence process of such mutual support and help behavior." [6]. Comparing the above three viewpoints, scholars define it from different angles, showing that the concept of social support varies according to the research object and purpose. Among them, the social resources view pays more attention to the types of social resources provided by each member of the social network when researching for social support and the role of various resources in the exchange and interaction between social network members, such as emotional support, information support, and tool support. The focus of this research is to analyze the impact of the social support received by Chinese athletes on obtaining high-quality employment opportunities and improving the quality of employment, and existing studies have shown that the social resources obtained by individuals through social networks can make it easier to make connections with higher-ranking helpers. Therefore, in order to better reflect these sources of social support that can help athletes improve the quality of employment, this article defines social support from the perspective of social resources; that is, social support is a form of resource exchange, which is generated in the process of interaction between athletes in a support network.

From the above definition of social support, it can be seen that the source of social support must be in the social network where the individual is located. Chinese athletes have received closed training and management since childhood, so their social network structure is of unique characteristics. Therefore, if we want to correctly analyze the impact of social support on the reemployment quality of this group, we must first sort out the source and composition of social support by constructing individual social support networks for athletes.

2.1. The Measurement Index of the Social Support Network of Chinese Athletes. Although individual social network research has some common concepts when describing the network structure, the Chinese athlete social support network is unique, and the concepts of some indicators that need to be measured are different [7]. This study mainly focuses on the following measurement indicators in the social support network:

(1) Network size: it is mainly used to measure the total number of people in the network. The larger the number, the richer the social support an individual has.

(2) Relationship constitution: it mainly refers to the proportion of athletes' various relationships in the network. This study mainly involves five types: family members, relatives, classmates or friends, teammates, and team managers. Among them, family members specifically refer to the athlete's parents, spouses, and children; relatives are those other than the aforementioned ones; teammates are the athletes' companions in the same training team; team managers are the athlete's coaches, sparring partners, team leaders, and other daily contact training teams managers; and classmates or friends are friends other than teammates and managers in the team. The social relationships that constitute the athlete's social network do not overlap with each other.

(3) Ties strength: tie strength can be divided into two types: "strong ties" and "weak ties." There are "interactive method" and "role method" [8] to measure the strong and weak ties. This research combines the 
reality of Chinese athletes and adopts the "role method." In the measurement of the "role method" in the past, "family members and relatives" were often defined as strong ties, and other relationships were defined as weak ties. Through our interviews with athletes, combined with their professional characteristics and closed group training, we here define "family members," "teammates," and "team managers" as strong ties and others as weak ties.

\subsection{Data Sources of the Social Support Network for Chinese} Athletes. The connection time before and after the retirement of Chinese athletes is very short, and the social support they obtain when researching for a job comes from the social network built during their service. Therefore, in order to better reflect the social network characteristics of athletes during this special period, this study used high-level Chinese professional athletes in service as samples when constructing the network. The athlete training management center selects athletes who have participated in large-scale sports events at or above the national level in the past as the survey objects and collects the data required for the construction of the social support network through a combination of on-site and online questionnaires distribution. 500 paper questionnaires and online questionnaires were distributed, 463 valid questionnaires with complete data content were received, and the effective rate of the questionnaire was $92.6 \%$.

\subsection{Analysis of Social Support Network of Chinese Athletes.} In the survey, this study refers to van der Poel's social support questionnaire and divides it into practical support and emotional support. Each type of subnetwork is described with a question. Among them, the question of emotional support is, when you are depressed because of certain problems, such as quarreling with people around you or dissatisfaction with training, life, etc., who do you usually talk to? The practical support question is, when you encounter difficulties in training, living, or finding a job, who do you think will help you? Through the research on the above issues, the number of helpers or associates who provide this type of social support to athletes will be obtained, so as to clarify the main source and composition of social support for professional athletes in China. The analysis results are shown in Table 1.

Firstly, with regard to the network size, the sizes of athletes' practical and emotional support network are 4.12 and 5.13, respectively, which are relatively small. Among them, the emotional support network size is slightly larger than that of the practical support network, which indicates that the practical social support is not so important in the training and daily life, which may be related to their life pattern. Since Chinese athletes' training centers are managed in a closed way and all foods and accommodation are provided uniformly, this may lead to low demands in this aspect.

Secondly, concerning the relation composition, in the two specific social support networks, the proportion of "teammates" is the highest, which is 40.06 and 59.49, respectively, indicating that in daily life no matter the type of support is, practical things or emotional psychological help, most of it comes from their teammates in the sports team. In addition, family and friends also offer more social support to athletes. In terms of practical support, family support is slightly more than that of classmates and friends, while in terms of emotional support, athletes rely more on classmates and friends. In addition, it should also be noted that athletes are destined to contact more the coaches and other personnel due to their daily life and training, so they offer more practical support to them.

Finally, in respect of the strong and weak ties, the strong ties between the two kinds of social support networks account for more than $70 \%$, showing a strong tendency toward "strong ties." Because it is difficult for Chinese athletes to get in touch with other groups in the society in the training process, their social objects are mostly concentrated in family members, teammates, and team managers, which leads to their narrow social circle and limited social support from weak ties.

Through the network analysis, it can be seen that athletes are limited by the closed social environment, and most of their social support comes from strong ties networks such as family members, teammates, and sports team managers. Among these social support sources, teammates and family members account for a higher proportion.

\section{Theoretical Basis and Research Hypothesis}

3.1. Social Support and Employment Quality of Professional Athletes. The employment quality originated from the labor concept advocated by the international labor field in the 1990s. With the gradual deepening of research in recent years, its connotation is constantly evolving and expanding, but in general the employment quality is the synthesis evaluation of the results of individual employment behaviors, including aspects like labor compensation and benefits, employment safety, career development, and work and life satisfaction [9]. Judging from the performance of the employment problems faced by retired athletes, they mainly concentrated in the low level of labor remuneration and social security, lack of stability in employment, lack of clear career promotion channels, and low overall job satisfaction. Therefore, it is crucial to find out the factors that promote the employment quality of athletes after retirement for improving the employment placement situation.

Relevant studies have shown that social support is a particularly important one among the many factors that affect individual employment quality, and this also applies to athlete groups. After athletes retirement, the social support provided by their social network not only gives them emotional accompaniment to ensure that they can conduct effective emotional communication and information exchange, but also provides them with more high-quality and reliable job opportunities to help them establish a new lifestyle in a better way [10]. Other studies found that frequent communication with parents, coaches, and peers and support from them can enhance athletes' confidence in dealing with issues related to career development, which not 
TABLe 1: Analysis results of social support network for Chinese athletes.

\begin{tabular}{|c|c|c|c|c|c|c|c|c|}
\hline \multirow{2}{*}{$\begin{array}{l}\text { Social support } \\
\text { network }\end{array}$} & \multirow{2}{*}{$\begin{array}{l}\text { Network } \\
\text { size }\end{array}$} & \multicolumn{5}{|c|}{ Relation composition (\%) } & \multicolumn{2}{|c|}{ Strong/weak ties (\%) } \\
\hline & & $\begin{array}{c}\text { Family } \\
\text { members }\end{array}$ & Relatives & $\begin{array}{c}\text { Classmates or } \\
\text { friends }\end{array}$ & Teammates & $\begin{array}{c}\text { Team } \\
\text { managers }\end{array}$ & $\begin{array}{c}\text { Strong } \\
\text { ties }\end{array}$ & $\begin{array}{l}\text { Weak } \\
\text { ties }\end{array}$ \\
\hline Practical support & 4.12 & 25.99 & 3.29 & 24.19 & 40.06 & 6.48 & 72.52 & 27.48 \\
\hline Emotional support & 5.13 & 12.47 & 2.48 & 22.84 & 59.49 & 2.72 & 74.68 & 25.32 \\
\hline
\end{tabular}

only enables athletes to correctly accept the new living environment, but also helps them transfer their related athlete qualities to improve their evaluation of their work and life while entering a new position [11]. These forms of tangible and intangible social support have greatly enhanced the overall quality of employment of athletes after retirement. Therefore, paying attention to the social support received by athletes is of great significance to the improvement of the quality of employment of athletes after retirement.

Based on the above analysis, this research proposes the following research hypothesis:

H1: social support has a significant positive impact on the employment quality of Chinese athletes

From the source and composition of the social support of athletes, it can be seen that most of the social support comes from "strong ties" groups such as family members, teammates, and sports team managers. Therefore, in this study, the social support of can be subdivided according to the source into family support, teammate support, and sports team support. Therefore, research hypothesis $\mathrm{H} 1$ can be further subdivided into the following:

H1a: family support has a significant positive impact on the employment quality of Chinese athletes

H1b: teammate support has a significant positive impact on the employment quality of Chinese athletes

H1c: sports team support has a significant positive impact on the employment quality of Chinese athletes

3.2. The Relationship between Social Support, Employment Perception, and Employment Quality of Professional Athletes. Social support has an impact on the employment quality of retired athletes by giving professional athletes emotional companionship, helping athletes establish career choices, and providing high-quality employment opportunities. This impact mainly refers to the positive benefits produced by using the main force of social support to work after retirement [12]. In the process of reemployment, some athletes will develop advance understanding of their role positioning, ability evaluation, employment environment, career development willingness, etc. before employment, and make corresponding preparations to better grasp the employment opportunities of social support and obtain a better quality of employment. This kind of cognitive process in which individuals take the initiative to understand and prepare for the employment process is employment cognition [13].

Studies show that employment cognition is one of the important factors related to the effect of social support on the employment quality of athletes after retirement.
Retirement process theory believes that the retirement of athletes is a natural process of sports career development, which means that athletes enter another social culture from one social culture, and the renewal of their understanding of careers and future choices is also a natural process of change. When athletes retire and transitions without clear employment cognition, their career choice behavior will be in a passive state; on the other hand, athletes with clear employment cognition will actively strengthen their selftransformation cognition, improve work cognition ability, and be active in understanding the status of employment and actively constructing a career vision, which enables them to maximize the use of opportunities provided by social support they receive, thereby further enhancing the impact of social support on the employment quality [14]. Therefore, through theoretical analysis, the study believes that employment cognition may play a positive moderating role in the relationship between athletes' social support and employment quality. Therefore, the study puts forward the following hypotheses:

H2: employment cognition has a positive moderating role in the influence of social support on the employment quality of Chinese athletes

H2a: employment cognition has a positive moderating role in the influence of family support on the employment quality of Chinese athletes

H2b: employment cognition plays a positive moderating role in the influence of teammate support on the employment quality of Chinese athletes

$\mathrm{H} 2 \mathrm{c}$ : employment cognition plays a positive moderating role in the influence of sports team support on the employment quality of Chinese athletes

Based on above hypotheses, the theoretical model framework constructed in this study is shown in Figure 1.

\section{Research Design}

4.1. Research Objects and Data Sources. In the research process of this study, Chinese high-level athletes who are reemployed after retirement and who have participated in national level and above large games were selected as the research object. They are from athletes training management centers in Shaanxi, Shanxi, Tianjin, and Fujian. Through the questionnaires issued and distributed on-site and online, a combination of related research data was collected. A total of 500 questionnaires were distributed, among which 437 were valid questionnaires with complete data content, with an effective rate of $87.4 \%$. The descriptive statistics for the sample data are shown in Table 2. 


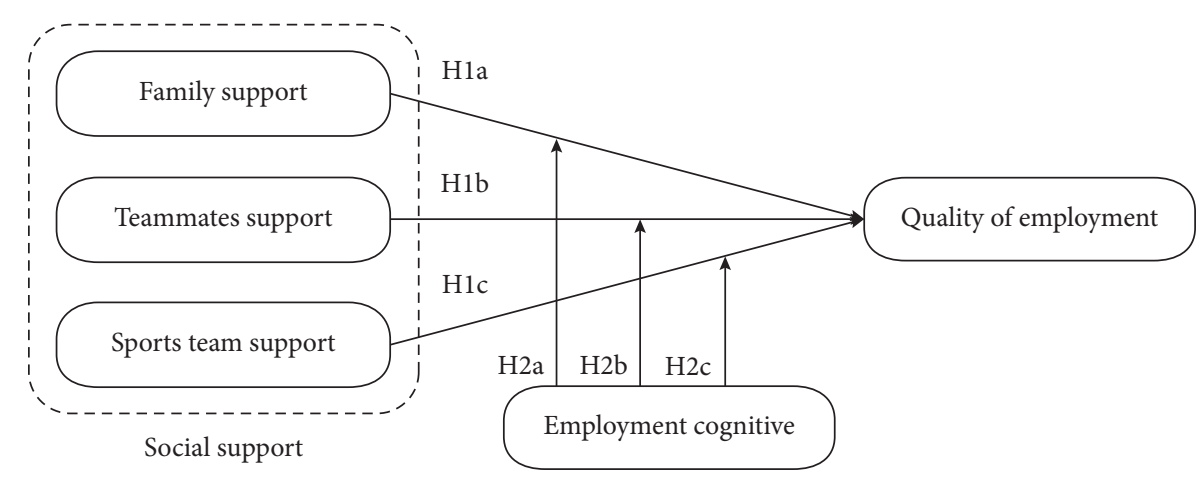

Figure 1: Schematic diagram of theoretical model.

TABle 2: Analysis results of descriptive statistics.

\begin{tabular}{|c|c|c|c|c|c|c|}
\hline Variables & $N$ & Statistics $(X \pm S)$ & \multicolumn{2}{|c|}{ Variables } & $N$ & Statistics (\%) \\
\hline Quality of employment & 437 & $3.68 \pm 0.98$ & \multirow{2}{*}{ Gender } & Female & 204 & 46.7 \\
\hline Family support & 437 & $3.44 \pm 1.21$ & & Male & 233 & 53.3 \\
\hline Teammates support & 437 & $3.47 \pm 1.09$ & \multirow{2}{*}{ Education level } & Bachelor's degree & 358 & 81.9 \\
\hline Sports team support & 437 & $3.53 \pm 1.14$ & & Master's degree or above & 79 & 18.1 \\
\hline Employment perception & 437 & $4.08 \pm 0.51$ & \multirow{2}{*}{ Training years } & $<9$ years & 43 & 9.8 \\
\hline Age & 437 & $29.63 \pm 3.48$ & & $\geq 9$ years & 394 & 90.2 \\
\hline
\end{tabular}

4.2. Variable Selection and Measurement Method. The core variables involved in this study include athletes' employment quality, employment perception, family support, teammate support, and sports team support. Among them, the explained variable is the employment quality of retired athletes; the core explanatory variables reflected three different sources of social support: family support, teammate support, and sports team support. The moderating variable was the athletes' employment perception near retirement. In addition to the above core variables, this paper also selects four variables that can reflect the individual characteristics of athletes, namely, gender, age, education level, and years of sports training, as the control variables.

In the measurement of core variables, the research used Likert 5-level scale to collect relevant information of the research objects. The options of each variable are "completely disagree $=1$," "basically disagree $=2$," "not sure $=3$," "basically agree $=4$," and "completely agree = 5." After calculating the scores of each scale, the measurement index of the sample was constructed by means of mean processing. Among them, social support was measured using the revised SSQA scale compiled by Du et al. (2020) [15], which was divided into three dimensions: family support, teammate support, and sports team support. Employment cognition refers to the quantity of career development and career attitude compiled by Thomas et al. (2010) [16], which is mainly measured from the four aspects of cognition of employment purpose, cognition of self-employability, cognition of employment situation, and intention of career development. Since there is no systematic measurement scale for employment quality, this study, on the basis of the research results of Erhel (2015) [17] and Bedeian (1991) et al. [18], measured athletes' subjective feelings on their relative salary level, job stability, social security, career development, and job satisfaction.

4.3. Data Analysis Methods. In order to examine the influence of mechanism of social support and employment perception on the employment quality of Chinese athletes, the data analysis of this study is mainly divided into two stages. In the first stage, the study will build a multiple linear regression model of the impact of social support on the employment quality of Chinese athletes and analyze the main effects of family support, teammate support, and sports team support on the employment quality of athletes. In the second stage, the study will introduce employment cognition to construct interaction terms, and test the moderating effect of employment cognition through hierarchical regression model, so as to further clarify the influence mechanism between social support, employment cognition, and athletes' employment quality, so as to verify the theoretical hypotheses proposed by the study and finally draw research conclusions.

4.4. Reliability and Validity Tests. Since the scale used in this study was processed and modified on the basis of the original scale, in order to ensure the validity of the obtained data, it is necessary to test its reliability and validity first.

Questionnaire reliability method is as follows: through the internal consistency method, Cronbach's $\alpha$ coefficient was used to test the reliability of the recovered sample data. It was found that the $\alpha$ coefficient of the variables involved in this study, such as family support, teammate support, sports team support, employment perception, and employment quality, was between 0.838 and 0.913 , all greater than 0.7 , 
showing high reliability. This indicates that the data measured by the 5 variable scales in this study are consistent, and the results obtained can be regarded as ones derived from a consistent measurement method and treated as an aggregate average.

Questionnaire validity is as follows: the $\mathrm{KMO}$ and Bartlett sphere test results show that the KMO value of the scale involved in the research is $0.740>0.5$ and the significance of the Chi-square statistic of the Bartlett sphere test is $0.000<0.1$. Through the significance test, further factor analysis can be performed. Through exploratory factor analysis of 22 items, a total of 5 common factors with characteristic roots greater than 1 were extracted. Among them, factors 1 to 5 are employment cognitive, family support, sports team support, teammates support, and quality of employment. The analysis results showed that the question factor loads of the five factors were all greater than 0.5 , and there was no cross factor phenomenon, indicating that the measurement questions of the questionnaire had good convergent validity and met the research requirements.

\section{Empirical Analysis of the Influence of Social Support and Employment Perception on Athletes' Employment Quality}

5.1. Analysis of the Influence of Social Support on the Employment Quality of Chinese Athletes. In order to verify the influence of the three different dimensions of social support on the employment quality of Chinese athletes and at the same time screen out the influence of other noncore variables, this study adopts the regression method and divides it into two models to verify it. Only four control variables were added to Model 1, which were gender, age, training years, and education level. The purpose of Model 1 was to investigate whether the control variables had an impact on the employment quality of athletes. On the basis of Model 1, Model 2 added core explanatory variables reflecting the three dimensions of social support to observe whether the influence of social support and control variables on athletes' employment quality changed. As the explained variable employment quality is a continuous value, OLS regression model is adopted for statistical analysis. The results of empirical analysis are shown in Table 3.

The results showed that the fitting degree of Model 1 and the significance of the overall model were poor $(R 2=0.018$, $F=1.960, P<0.100)$, indicating that the control variables had almost no impact on the employment quality of Chinese athletes. Therefore, it can be judged that gender, age, training years, and education level have no influence on the employment quality of athletes. The fitting degree of Model 2 and the significance of the overall model were high $(R 2=0.789, F=228.926, P=0.000<0.01)$, and the three core explanatory variables all passed the significance level test of $1 \%(P<0.01)$.

In previous related studies, personal factors such as the gender and education level of job seekers often have an impact on the quality of their employment. However, the analysis results of Model 1 show that these personal factors
TABLE 3: Analysis results of the influence of social support on the employment quality of Chinese athletes.

\begin{tabular}{lcc}
\hline Variable & $\begin{array}{c}\text { Model 1 } \\
\text { Standardization } \\
\text { factor }\end{array}$ & $\begin{array}{c}\text { Model 2 } \\
\text { Standardization } \\
\text { factor }\end{array}$ \\
\hline Gender & $-0.068(-1.405)$ & $0.003(0.150)$ \\
Age & $0.022(0.450)$ & $0.009(0.386)$ \\
Training years & $0.066(1.385)$ & $-0.004(-0.169)$ \\
Education level & $-0.095(-1.975)$ & $-0.044(-1.959)$ \\
Family support & - & $0.348^{* * *}(8.484)$ \\
Teammate support & - & $0.316^{* * *}(7.246)$ \\
Sports team & - & $0.287^{* * *}(7.106)$ \\
support & 0.018 & 0.789 \\
$R 2$ & 1.960 & $228.926^{* * *}$ \\
$F$
\end{tabular}

Note. ${ }^{*} P<0.1,{ }^{* *} P<0.05$, and ${ }^{* * *} P<0.01$.

in the athlete group do not have a significant impact on the quality of their employment. Research believes that the main reason for this phenomenon is that the reemployment of Chinese athletes is unique. Most professional athletes will engage in work related to their sports after retirement, such as coaches and sports management staff. In these areas of work, compared to the education level, recruiters value the athlete's professional ability and understanding of sports management more. Such employment environment and work content have also reduced the unequal treatment of athletes due to gender to a certain extent, which is different from previous studies.

According to the standard regression coefficient of the three core explanatory variables in Model 2 , the coefficient of family support is the largest, which is 0.348 , indicating that family support has the greatest influence on the employment quality of Chinese athletes. Every $1 \%$ increase in the score of family support will increase the score of the employment quality of athletes by $0.36 \%$. Although the influence of teammate support and sports team support on athletes' employment quality is slightly lower than that of family support, the coefficient is still around 0.3, and the positive influence on Chinese athletes' employment quality is also very significant. Accordingly, it can be concluded that social support has a significant positive impact on the employment quality of Chinese athletes, which indicates that the higher the family support, teammate support, and sports team support are, the higher the employment quality of retired athletes will be. Therefore, hypothesis 1 of the study is verified.

Research has shown that there is a strong relationship between the support of family, teammates, and sports teams and the transition to retirement. When athletes are faced with transition decisions after retirement, the support of parents, peers, coaches, or team leaders will have a positive impact on athletes' career exploration and choice [19]. Existing literature shows more that athletes receive help from peers, sports teams, and families during the transition to retirement [20]. On this basis, this study further found that the information, resources, and actions from the social network will directly promote the employment quality of athletes after retirement. Because Chinese athletes training 
in a closed system, the sports career during difficult to access to other kinds of work, so after the athlete retires, facing the sudden arrival of career transition, on the one hand they will produce in the psychological anxiety and tension, on the other hand they completely on your own is difficult to find suitable and quality work. At this time, family, the team teammates, as well as the long-term exposure to team management support for the athletes, which can give great extent to alleviate the employment pressure of athletes, and retired after the transformation of career development to provide substantial material support, help them get higher pay and better benefits, personal more satisfying jobs, and it has brought substantial promoting effect to the improvement of employment quality.

\subsection{Analysis of Employment Perception Moderating Effect on} the Relationship between Social Support and Employment Quality of Chinese Athletes. In order to further explore the influence of mechanism of social support on athletes' employment quality, the study further tested the moderating effect of employment cognition on the basis of the main effect analysis of social support. In this study, employment quality was taken as the dependent variable; family support, teammate support, and sports team support as the independent variable; and employment perception as the moderating variable to build the following hierarchical regression model:

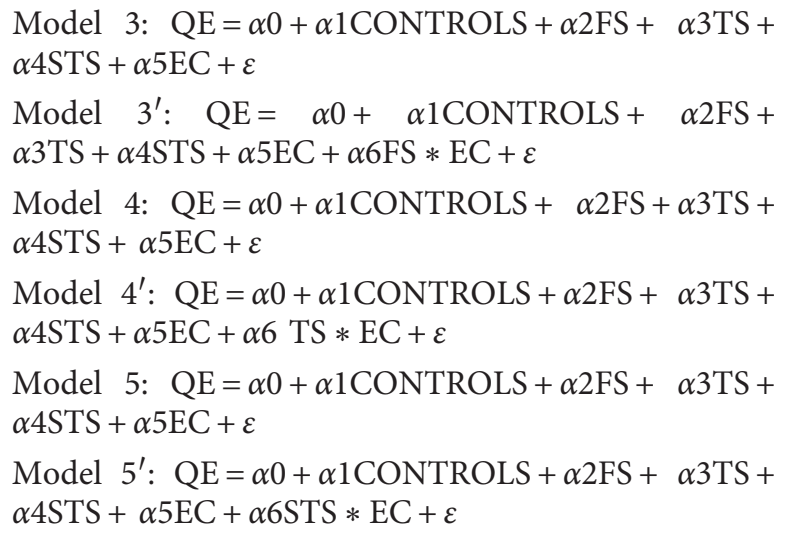

In order to eliminate the influence of multicollinearity, the variables FS, TS, STS, and EC were obtained by centralized processing on the basis of the aggregate mean of the original data. $\mathrm{FS} * \mathrm{EC}, \mathrm{TS} * \mathrm{EC}$, and $\mathrm{STS} * \mathrm{EC}$ are the interaction terms of family support, teammate support, sports team support, and employment perception, respectively, representing the moderating effect of employment perception on the relationship between social support and athletes' employment quality. When the coefficient $\alpha 6$ of Models $4^{\prime}$, $5^{\prime}$, and $6^{\prime}$ is significant, it indicates that employment perception has a moderating effect. When the coefficient is positive, it has positive regulation effect; otherwise, it has negative regulation effect. Due to space constraints, only the analysis results of Models $4^{\prime}, 5^{\prime}$, and $6^{\prime}$ are presented here, as shown in Table 4.

The results show that the fitting effects of the three models are all good (R2 [Model 6'] = 0.799; R2 [Model 7'] =
0.803; R2 [Model $8^{\prime}$ ] $=0.794$ ). The results of Model $6^{\prime}$ $(F=189.169, P=0.000<0.01)$ show that the coefficient of interaction between employment cognition and family support is 0.095 . The significance level test of $1 \%$ indicates that the establishment of good employment cognition in advance can guide athletes to better understand themselves and clarify their future career development direction, so that they have the initiative to choose in the process of employment, which effectively protects the effectiveness of the career development of retired athletes. After retirement, the most direct practical problem athletes face is the poor employment situation caused by single skills, little work experience, and lack of accurate employment service platform.

Family, as a harbor for athletes, provides financial, material, emotional, and other support for the entire life course of athletes. The accumulation and help of family capital can enhance the labor value of retired athletes and improve their employment quality. When athletes accurately assess their own positioning in advance and understand the employment environment, they can better grasp their personal abilities and specialties, determine the best career development direction, and more easily choose a career path that meets their interests and specialties during the accumulation of family capital, which enhances the employment quality of retired athletes. Therefore, employment perception has a significant positive moderating effect on the impact of family support on the employment quality of Chinese athletes, which supports hypothesis $2 \mathrm{a}$.

The results of Model $7^{\prime}(F=193.747, P=0.000<0.01)$ show that the interaction coefficient of employment $\operatorname{cog}$ nition and teammate support is 0.119 , and through the significance level test of $1 \%$, it is shown that the influence of teammate support on athletes' employment quality will be positively adjusted by athletes' own employment cognition. After Chinese athletes enter professional training, they spend most of their time with their teammates day and night. In their spare time, more spiritual support comes from the communication with their teammates. A harmonious relationship can bring great psychological comfort to athletes, make them feel a sense of belonging, and create a comfortable and stable psychological environment. After retirement, athletes often fall into the "social anxiety," inferiority, and frustration syndrome due to the difference in social status and confusion about their future development, which will reduce their satisfaction with the new job and life style and then affect the quality of employment. However, employment cognition can often improve their sense of selfcontrol and psychological quality, which undoubtedly enhances the ability of athletes to resist transition and emotions, so that the psychological comfort given by teammates can play a better role, help them enhance their confidence in career transition, and better relieve the negative psychology in the face of the new work environment. Furthermore, the positive influence of peer support on employment quality was expanded. Therefore, research hypothesis $2 \mathrm{~b}$ holds.

The results of Model $8^{\prime}(F=182.695, P=0.000<0.01)$ showed that the coefficient of interaction between employment perception and sports team support was 0.055 , which 
TABLE 4: The moderating effect of employment perception on the relationship between social support and athletes' employment quality.

\begin{tabular}{lccc}
\hline Variable & $\begin{array}{c}\text { Model 3' } \\
\text { Standardization factor }\end{array}$ & $\begin{array}{c}\text { Model } 4^{\prime} \\
\text { Standardization factor }\end{array}$ & $\begin{array}{c}\text { Model } 5^{\prime} \\
\text { Standardization factor }\end{array}$ \\
\hline Gender & $-0.011(-0.504)$ & $-0.018(-0.802)$ & $-0.003(-0.152)$ \\
Age & $-0.002(-0.075)$ & $-0.001(-0.036)$ & $-0.005(-0.210)$ \\
Training years & $-0.007(-0.313)$ & $-0.007(-0.303)$ & $-0.004(-0.185)$ \\
Education level & $-0.044(-1.975)$ & $-0.034(-1.543)$ & $-0.043(-1.904)$ \\
Family support & $0.349^{* * *}(8.706)$ & $0.346^{* * *}(8.702)$ & $0.348^{* * *}(8.560)$ \\
Teammate support & $0.329^{* * *}(7.631)$ & $0.339^{* * *}(7.932)$ & $0.322^{* * *}(7.338)$ \\
Sports team support & $0.283^{* * *}(7.166)$ & $0.271^{* * *}(6.903)$ & $0.293^{* * *}(7.312)$ \\
Employment perception (centralized) & $-0.034(-1.444)$ & $-0.015(-0.642)$ & $-0.039(-1.635)$ \\
Family support $*$ employment perception & $0.095^{* * *}(4.251)$ & - & - \\
Teammate support $*$ employment perception & - & $0.119^{* * *}(5.165)$ & - \\
Sports team support $*$ employment perception & - & - & 0.803 \\
$R 2$ & 0.799 & $193.747^{* * *}$ & $0.055^{* *}(2.428)$ \\
$F$ & $189.169^{* * *}$ & 0.794 \\
\hline
\end{tabular}

Note. ${ }^{* * *} P<0.01,{ }^{* *} P<0.05$, and ${ }^{*} P<0.1$.

passed the significance level test of $5 \%$, indicating that the influence of sports team support on athletes' employment quality would be positively moderated by athletes' employment perception. Judging from the current employment choices of Chinese athletes, most of them hope to be engaged in jobs related to professional sports after retirement, such as coaches and team leaders. In addition, the former sports teams' support of management personnel plays an important role in meeting their career development needs. Under this condition, if the athletes have a clear cognition of purpose and personal ability to engage in professional sports-related work in the future, they will better grasp the job opportunities offered by the sports teams, thus improving the quality of future employment. Therefore, employment perception has a significant positive moderating effect on the influence of sports team support on the employment quality of Chinese athletes. This conclusion supports research hypothesis $2 \mathrm{c}$.

\section{Conclusions}

In order to explore the influence of mechanism of social support on the employment quality of Chinese athletes after retirement transition, this study uses the social support network of Chinese athletes to clarify the source and composition of the social support of this group and takes social network theory, social support theory, and retirement process theory as the theoretical basis. This paper analyzes the influence of social support on the employment quality of Chinese athletes from different dimensions and further explores the mechanism of social support on the employment quality of athletes from the regulating effect of athletes' self-employment cognition. Through network analysis and empirical test, the research mainly draws the following conclusions.

Firstly, through the construction of Chinese athletes' social support network, the research finds that, because of the closed management mode and social environment, the social support network showed a strong tendency to "strong ties." The group gained emotional and practical support mostly from family, teammates, and sports management and their training daily life related group, among which family and social support from their teammates are higher. Therefore, in order to provide more social support for the future work transformation of Chinese athletes, the study believes that professional athletes should be given a more relaxed social environment and social opportunities in daily management to help them establish a wider social network.

Secondly, social support will have a significant positive impact on the employment quality of Chinese athletes after retirement transition from three dimensions: family support, teammate support, and sports team support. The more the emotional care and practical help received from their families, teammates, and sports teams in their social networks are, the higher the quality of their postretirement transition employment will be.

Thirdly, employment perception has a significant positive moderating effect on the influence of social support on the employment quality of Chinese athletes. When the athletes have a full understanding and preparation of their role positioning, employability, employment environment, and career development intention, they can better grasp the social support and employment help from their families, teammates, and sports teams, thus further improving the promotion effect of social support on their employment quality. Therefore, the study believes that, in addition to paying attention to the training of athletes' professional capabilities, Chinese athletes' management departments should also establish a more complete career development plan to help them envision their future transformation and development directions, so as to make better use of the high-quality job opportunities brought by social resources.

\section{Data Availability}

The original data used in this study are the questionnaire data obtained from the survey, which are available from the corresponding author upon request.

\section{Conflicts of Interest}

The authors declare that they have no conflicts of interest. 


\section{References}

[1] B. Ren and X. Zhu, "Research on the measurement and path of China's high quality openness in the new era," Statistics of Information Forum, vol. 35, no. 09, pp. 26-33, 2020.

[2] X. Zhang and J. Yan, "Comparison of the influences of human capital and social capital on the income of retired athletes in China," Journal of Shanghai University of Sport, vol. 44, no. 4, pp. 31-40, 2020.

[3] J. Wang, "A quantitative analysis on the retirement awareness and psychological state of Chinese athletes," Acta Psychology Sinica, vol. 4, pp. 496-506, 2008.

[4] I. G. Sarason, B. R. Sarason, E. H. Potter, and M. H. Antoni, "Life events, social support, and illness," Psychosomatic Medicine, vol. 47, no. 2, pp. 156-163, 1985.

[5] B. H. Gottlieb, "Assessing and strengthening the impact of social support on mental health," Social Work, vol. 30, no. 4, pp. 293-300, 1985.

[6] C. D. Ryff and B. Singer, "Interpersonal flourishing: a positive health agenda for the new millennium," Personality and Social Psychology Review, vol. 4, no. 1, pp. 30-44, 2000.

[7] H. He and G. Deng, "Multi-dimensional ordered clustering method based on common trend extraction," Statistics \& Information Forum, vol. 35, no. 12, pp. 15-20, 2020.

[8] F. Xiong, W. Shen, H. Chen, S. Pan, X. Wang, and Z. Yan, "Exploiting implicit influence from information propagation for social recommendation," IEEE Transactions on Cybernetics, vol. 50, no. 10, pp. 4186-4199, 2020.

[9] Z. Peng, G. Lu, and L. Li, "Research on graduates' employment quality: influence factor and path analysis," China Higher Education Research, no. 1, pp. 57-64, 2020.

[10] G. Cheng, C. Rong, and L. Wang, "The effet of social capital in virtual community on customer citizenship behavior: from the perspective of psychological ownership," Statistics \& Information Forum, vol. 35, no. 11, pp. 121-128, 2020.

[11] F. Xiong, X. Wang, S. Pan, H. Yang, H. Wang, and C. Zhang, "Social recommendation with evolutionary opinion dynamics," IEEE Transactions on Systems, Man, and Cybernetics: Systems, vol. 50, no. 10, pp. 3804-3816, 2020.

[12] X. Zhang and H. Qian, "Structural characteristics of athletes' employment network: a survey of 130 professional athletes in Shaanxi province," Journal of Wuhan Institute of Physical Education, vol. 52, no. 3, pp. 17-23, 2018.

[13] D. Wang, "The relationship among cognitive appraisal, psychological control, social support and employment stress in university studies," China Journal of Health Psychology, vol. 12, pp. 1142-1145, 2007.

[14] Y.Zou and F. Xiao, "Difference analysis of salary evaluation of athletes under different contingency factors," Journal of Xi'an Physical Education University, vol. 37, no. 6, pp. 712-720, 2020.

[15] W. Du, J. Qiu, F. Zhang, J. Zhong, B. Zhang, and Y. Shen, "Development and validation of social support questionnaire for athletes," Journal of Wuhan Institute of Physical Education, vol. 54, no. 11, pp. 94-100, 2020.

[16] L. K. M. Thomas and W. F. Russell, Applications of Rasch Measurement in Education, Nova Science Publishers, New York, NY, USA, 2010.

[17] C. Erhel and M. Guergoatlariviere, "Trends in job quality during the great recession and the debt crisis( 2007-2012): a comparative approach for the EU," Psychopharmacology, vol. 232, no. 19, pp. 3563-3572, 2015.

[18] A. G. Bedeian, E. R. Kemery, and A. B. Pizzolatto, "Career commitment and expected utility of present job as predictors of turnover intentions and turnover behavior," Journal of Vocational Behavior, vol. 39, pp. 331-343, 1991.

[19] J. Wang, "Investigation on retirement consciousness, mental and strategy of our athletes," China Sport Science, vol. 7, pp. 47-59, 2006.

[20] Y. Hu, F. Xiong, S. Pan, X. Xiong, L. Wang, and H. Chen, "Bayesian personalized ranking based on multiple-layer neighborhoods," Information Sciences, vol. 542. 